\title{
Author Response: Management of Postoperative discitis
}

\author{
Santhanam Rengarajan ${ }^{1}$, Lakshmi Krishnaswamy ${ }^{2}$ \\ ${ }^{1}$ Department of Neurosurgery, Sree Balaji Medical College and Hospital, Bharath University, Chennai, India \\ ${ }^{2}$ Department of Microbiology, Sree Balaji Medical College and Hospital, Bharath University, Chennai, India
}

Dear Editor,

We appreciate the readers for having assessed our manuscript and provided their valuable comments, and we are pleased to respond to the points they have raised. Below are the responses to the two points they have brought out. First, we thank them for acknowledging our interpretation that postoperative discitis is an often misdiagnosed or underdiagnosed cause of persistent pain after lumbar discectomy.

The risk factors for developing neurological deficits in cases of spondylodiscitis like age, diabetes, rheumatoid arthritis, steroid use, etc. are more relevant in cases of spontaneous spondylodiscitis [1]. On the other hand, patients with postoperative discitis following lumbar discectomy more often present with pain and instability without much neurological deficits. We agree with the readers that nutrition panel, blood urea nitrogen/creatinine levels, and liver function tests are other helpful investigations. However, as erythrocyte sedimentation rate and C-reactive protein are considered major inflammatory markers, we have highlighted those investigations for being helpful in assessing response to treatment in patients.
In addition, the readers have indicated their preference for adding interbody fusion to improve anterior support and stability. We would like to emphasize that in cases with postoperative discitis, posterior approach, debridement and immobilization is considered to be sufficient and is known to promote accelerated fusions [2]. We hope to have adequately addressed the points raised by our readers and thank them for their precious input and comments.

\section{Conflict of Interest}

No potential conflict of interest relevant to this article was reported.

\section{References}

1. Gouliouris T, Aliyu SH, Brown NM. Spondylodiscitis: update on diagnosis and management. J Antimicrob Chemother 2010;65 Suppl 3:iii11-24.

2. Rayes M, Colen CB, Bahgat DA, et al. Safety of instrumentation in patients with spinal infection. J Neurosurg Spine 2010;12:647-59. 